\title{
Bridging the disciplinary gap in conservation agriculture research, in Malawi. A review
}

\author{
Thirze D. G. Hermans ${ }^{1}$ (D) $\cdot$ Stephen Whitfield ${ }^{1} \cdot$ Andrew J. Dougill $^{1} \cdot$ Christian Thierfelder $^{2}$
}

Accepted: 14 January 2020 / Published online: 29 January 2020

(C) The Author(s) 2020

\begin{abstract}
Conservation Agriculture has emerged as a popular form of climate smart agriculture aimed at enhancing climate change resilience for smallholder farmers across Africa. Despite positive biophysical results, adoption rates remain low. It has been acknowledged that improved understanding of farmer decision-making is needed due to the variation in socio-economic and agro-ecological contexts which drives the research agenda to answer the question 'what forms of Conservation Agriculture work, where, and why?'. To fully understand this question, we need to approach the study of Conservation Agriculture within complex farming systems by collating and integrating different forms of knowledge. In this paper, we discuss (1) a comparison of disciplinary approaches to evaluating Conservation Agriculture in Malawi, (2) the identification of the knowledge gaps that persist at the intersection of these disciplines and (3) recommendations for alternative and interdisciplinary approaches in addressing these knowledge gaps. With a focus on published studies from Malawi, we show that the Conservation Agriculture literature represents two distinct approaches to addressing the question 'what forms of Conservation Agriculture work, where, and why?', namely agro-ecological and socio-economic and that neither of these approaches can address the full scope of this question, in particular its 'why' component. To overcome these challenges, there is a need for access to compatible, comprehensive data sets, methodological approaches including farmer participation and ethnography, through on-farm trial research as a middle ground between disciplinary approaches.
\end{abstract}

Keywords Farming systems $\cdot$ Climate-smart agriculture $\cdot$ Southern Africa $\cdot$ No-tillage $\cdot$ Malawi

\section{Contents}

1. Introduction

2. Theoretical Framework

3. Methodology

4. Framing Conditions 'What forms of Conservation Agriculture work, where, for whom, and why?'

4.1 Framing Condition 1: What is Conservation Agriculture?

Thirze D. G. Hermans

eetdgh@leeds.ac.uk

Stephen Whitfield

S.Whitfield@leeds.ac.uk

Andrew J. Dougill

A.J.Dougill@leeds.ac.uk

Christian Thierfelder

c.thierfelder@cgiar.org

1 Sustainability Research Institute, University of Leeds, Leeds LS2 9JT, UK

2 CIMMYT, P.O. Box MP 163, Mount Pleasant, Harare, Zimbabwe
4.2 Framing Condition 2: What Does it Mean for Conservation Agriculture to Work?

4.3 Framing Condition 3: Where and for Whom?

4.4 Clustered Framing Conditions

4.5 Framing Condition 4: Why?

5. Characterizing and comparing disciplinary approaches to evaluating Conservation Agriculture in Malawi

6 . The knowledge gaps that persist at the intersection of these disciplines

7. Recommendations for alternative and interdisciplinary approaches in addressing these knowledge gaps

8. Conclusion

Acknowledgements

References

\section{Introduction}

Conservation Agriculture (CA) has been widely promoted across Africa as a way of improving the livelihoods of smallholder farmers, combining increased climate change resilience 
and soil carbon sequestration (Kassam et al. 2009; Lipper et al. 2014; Mupangwa et al. 2017a). It is based on three principles: (1) minimum soil disturbance, (2) soil surface cover with crop residues and (3) crop rotation or diversification via intercropping (Fig. 1) (FAO 2015). Agronomic studies have shown that CA can improve soil water retention, decrease soil erosion and runoff, improve soil structure, quality, and biological activity allowing earlier crop planting (FAO 2008; Thierfelder and Wall 2009; Thierfelder et al. 2015c, 2017). Further literature has shown its potential to enhance soil fertility, heat and dry spell resilience, and crop productivity (Thierfelder and Wall 2010a; Thierfelder et al. 2015c; Steward et al. 2018). Extrapolating from this evidence of soil and yield improvements, narratives of socio-economic benefits, such as labour saving, women's empowerment, food security and improved rural livelihoods, have become mainstreamed into the promotion of CA (Whitfield et al. $2015 b)$. There is also a recognition that these benefits do not play out for all people in all places and that there is a need to adapt CA principles to local agro-ecological and socio-economic contexts (Andersson and Giller 2012). Adoption rates have remained low in southern Africa (Andersson and Giller 2012; Ward et al. 2018), unlike in Brazil and Argentina where adoption rates have reached $>$ 70\% (Kassam et al. 2019)

Previous discussions on farmers' adoption of new agricultural innovations have shown that farmers' motivations for adoption are diverse (Biggs 1989; Fujisaka 1994). Low adoption rates and recognition that there are multiple ways in which agro-ecological and socio-economic context interacts with $\mathrm{CA}$ land management practices, continues to drive research efforts to understand what forms of CA work, where, for whom and why? The body of literature that can be considered as contributing to these questions is growing and diverse, covering both agronomic aspects of soil-plant-water interactions, and socio-economic aspects of decision-making, labour and resource constraints
Within this body of literature, the way in which the problem of low adoption is framed may be contributing to the difficulty of understanding the reasons for it. The notions of adoption (and non-adoption or dis-adoption) inadequately reflect the complex ways in which farmers interact with, trial, experiment with and adapt agricultural technologies and techniques (Giller et al. 2009; Pannell et al. 2014; Brown et al. 2017, 2018a). Within academic CA literature, there are relatively few studies that aim to understand CA-related practices within the broader knowledge and decision-making context of farming systems. These limitations are not confined to issues of adoption, but also relate to understanding the interactions between farming practices, the local agro-ecological conditions and more broadly the knowledge and decisionmaking processes of farmers

In this paper, we systematically review existing literature focused on Malawi on the question 'what forms of CA work, where, for whom, and why?' We map out the approaches that are commonly taken to address this question and the contributions that have been made across a broad and growing body of literature. We consider the potential compatibilities between different approaches and what can be learnt through a cross-disciplinary reading of this evidence base. We also consider the limitations of existing evidence, by revealing some of the incompatibilities between different disciplinary approaches, asking 'why do knowledge gaps persist?', and what the alternative ways of interpreting and understanding the 'CA paradox' of low adoption are.

In Malawi, the agricultural sector provides work for $80 \%$ of the working population and contributes approximately 35\% of the GDP (Ngwira et al. 2012a; Tesfaye et al. 2015). Malawi is one of the southern African countries where CA has been argued to be favourable because of its low ruminant livestock density, high rural population density and challenges with soil degradation
Fig. 1 Left: Malawian conventional ridge and furrow treatment without residues. Right: conservation agriculture treatment with residue cover, minimum tillage and crop rotation or intercropping. The photos of the conventional and conservation agriculture treatment were taken on CIMMYT on-farm trials in Malawi
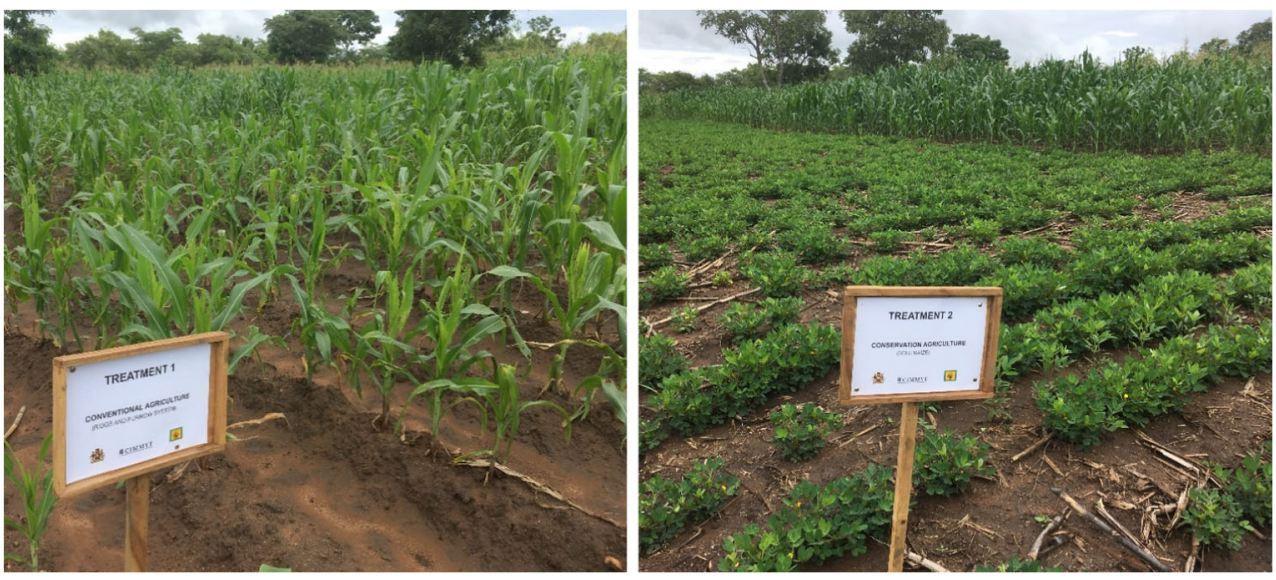
(Ngwira et al. 2012a, c; Valbuena et al. 2012; The World Bank 2016; Asfaw et al. 2018). However, a number of recent studies (e.g. Dougill et al. 2017; Chinseu et al. 2019) have highlighted institutional and socio-cultural reasons for the low levels of CA adoption.

This study investigates the approaches adopted by CA literature to understand: 'what forms of CA work, where, for whom, and why?'. The aims of this study are therefore to (1) compare disciplinary approaches to evaluating CA in Malawi, (2) identify the knowledge gaps that persist at the intersection of these disciplines and (3) make recommendations for alternative and interdisciplinary approaches in addressing these knowledge gaps.

\section{Theoretical framework}

The dynamic interactions between social histories, rural livelihoods and economies, climatic and agro-ecological conditions, resources and technological change, decision making, including trade-offs, all underpin farming systems research (FSR). FSR has become popular since the 1970 s as a way to address the dynamic conditions of farming and the involved decision-making (Whitfield et al. 2015a). Since the start of FSR as a discipline, its application and methods have diversified from addressing adoption constraints and farmer participation to examining farming processes, functionality and infrastructure (Collinson 2000; Whitfield et al. 2015a). However, agricultural research continues to be largely approached through discipline specific approaches (e.g. social science, agronomy, economics, climate impacts) that focus on component parts of the system. These disciplines are associated with specific norms, methodological approaches and ontologies.

Individual disciplinary approaches can contribute to an understanding of the what, where and for whom questions of CA. For example, in analysing agronomic field trial data from global CA studies, Steward et al. (2018) showed that CA's performance improves, relative to conventional practices, with drought and heat severity and with low soil clay contents. Thierfelder et al. (2017) found that in agronomic trials across southern Africa that CA maintains higher soil moisture contents during dry spells but can lead to yield reductions during heavy rainfall. Additionally, they suggest that CA increases profitability, although only after 2-5 years, depending on farmer skills and management precision (Thierfelder et al. 2017). Other scholars, such as Whitfield et al. (2015b), apply a critical reflection on the evidence base for CA narratives, to enable the mapping of the 'what' and 'for whom' evidence. From other social science papers, such as Fisher et al. (2018) and Holden et al. (2018), we have learnt about information and technology distribution through farmer-to-farmer extension and lead farmers. Therefore, individual disciplinary approaches have contributed to specific part of the what, where and for whom questions of CA.

As Whitfield et al. (2015b) show in the context of Zambia, the creation of the evidence base for the CA narratives started in controlled environments (managed by research institutes) focusing on agronomic benefits (e.g. Vogel 1994; Thierfelder and Wall 2009; Thierfelder and Wall 2010a; Thierfelder and Wall 2010b). On the other hand, the adoption and (socio-) economic studies mainly focused on the inputs, labour, production and profitability evaluation, but there has rarely been interactions across these isolated disciplinary studies (Ngwira et al. 2012a, b; Grabowski et al. 2016). Andersson and D'Souza (2014) suggest that CA's narrative in southern Africa has been shaped by the development community in socio-economic and institutional contexts.

Despite efforts by various disciplines to increase our knowledge on the aspects of what, where and for whom CA is suitable, the discussed CA paradox of low adoption despite positive biophysical results persists. There are certainly more knowledge gaps in the 'what', 'where' and 'for whom' aspects of this broader question still to be filled, but we hypothesise that it is particularly in the 'why' component of the questionin understanding why $\mathrm{CA}$ is favourable to, and practiced by certain people in certain contexts, and not by others-where the most fundamental gaps in knowledge persist.

Different theories about why CA does or does not work tend to emerge from different disciplines, themselves reflecting different sets of assumptions, methodological approaches and problem framings (Leach et al. 2010; Sumberg et al. 2012). These theories, whether about labour availability, soil properties, institutional environments, climate, innovation dynamics or any number of other aspects, are rarely wholly adequate on their own. However, collating across this broad body of CA research is also difficult because of the ontological and methodological differences that characterise different research approaches. Integrating across different knowledges and disciplines has three main challenges according to Black (1998, 2002): the foundation and infrastructure for communication between disciplines, the language and terminology collating across disciplines and their understanding and the different perceptions on the discussed issue. As a direct response to these challenges, in this paper, we map out the approaches to research on CA in Malawi, to explore whether there is a disciplinary and conceptual gap and to characterise this in terms of language and issue perception, as a basis for reflecting on how the integration and communication across the $\mathrm{CA}$ research landscape might be achieved. 


\section{Methodology}

To evaluate the literature on CA in Malawi, we conducted a realist systematic literature review (Thompson et al. 2010; Biesbroek et al. 2013; Antwi-Agyei et al. 2015). This approach focuses on depth and qualitative analysis as opposed to quantity as is the case with a systematic approach. Literature searches were conducted in the publications databases Scopus and Web of Science (WoS). The search terms were selected to cover the diversity of terminology used to describe CA, constraints, farmers and geographical area (Table 1). Various search terms were tested to ensure capturing a wide variety of literature for the next selection phase. All collected literature (WoS 94 papers, Scopus 56) from the search was reviewed based on titles, abstracts and full texts and a selection was made based on the selection criteria (Table 2). After selection, 40 articles were deemed relevant.

The articles were reviewed based on four key points, identified to highlight the component parts of the broader questions, namely, (1) what CA is (i.e. how CA practice is defined and described), (2) what it means to work (i.e. how CA success is defined and measured), (3) where and for whom (i.e. the contextual and determinant factors of success that are considered) and (4) why (i.e. the explanatory mechanisms for success in particular contexts that are presented). The first framing condition focuses on the variety of used CA definitions, followed by framing condition 2 on what is considered as CA being successful (i.e. success metrics). Framing condition 3 examines the conditions of the CA studies and the provided information on these conditions. Lastly, framing condition 4 considers if studies present the drivers and explanations behind CA's performance and suitability. Following the grounded theory approach (Glaser and Strauss 1967), information according to the four key topics and framing conditions was collected for all papers and used for qualitative coding. After all the codes in response to the four key points were collected, each paper was assigned binary numbers for each of these codes $(1=$ yes and $0=$ no). The binary values assigned to the identified codes enabled us to apply a cluster analysis and create a dendrogram in SPSS Statistics 23.0.0.2 (IBM Corp 2015). The cluster analysis method selected is the hierarchical cluster analysis according to Ward's method, which is also used in standard

Table 1 Search string for the literature search in SCOPUS and Web of Science on 2/03/2018, a second search and literature update was performed on $29 / 08 / 2019$

Conservation Agriculture OR Sustainable Intensification OR Climate Smart Agriculture OR no*till* AND soil OR (adopt* OR implement* OR practice OR constrain OR challenge OR limit*) AND Farmer* OR Small*holders AND Malawi statistical analysis such as ANOVA (Ward 1963). The distance measure selected for the binary data is the Euclidean distance (i.e. direct geometric distance).

\section{Framing conditions 'what forms of CA work, where, for whom and why?'}

\subsection{Framing condition 1: what is CA?}

The framing question 'What is CA?' focuses on the definition of CA including the practices that are evaluated in the studies. The time aspect in the definition (e.g. how long before we call it CA?) is in most cases not part of the definition, but some studies consider the effect of time on the results (framing condition 3). In some cases, CA's three main practices are used or the practices adopted by farmers defines the working definition $(n=19)$. There is a group of literature, which provides detailed technical prescriptions $(n=20)$ or information on additional agronomic practices and guidelines $(n=27)$ that are needed for successful functioning of CA. These practices include fertilizer, herbicide, organic manure (Mupangwa et al. 2017b; Fisher et al. 2018), agroforestry tree species (Andersson and D'Souza 2014) and seeding patterns including spacing and planting methods (Ngwira et al. 2012c, 2013; Thierfelder et al. 2013b, 2015c, 2016a; Bunderson et al. 2017; Mupangwa et al. 2017b; Mutenje et al. 2019), ripping (Thierfelder et al. 2015c; Mutenje et al. 2019) and basin planting (Thierfelder et al. 2015c; Mutenje et al. 2019). In the paper by Thierfelder et al. (2016a), CA is defined as no-till with residue cover and dibble stick planted maize only in one treatment and maize (Zea mays L.)-cowpea (Vigna unguiculata L.) intercropping in the other-the later following the stringent definition of FAO with all three principles covered while the former being an "incomplete CA-based system". Additionally, maize row spacing $(75 \mathrm{~cm}$ and $25 \mathrm{~cm}$ between stations), seed quantity ( 1 seed per planting station) and the fertilizer rates $\left(69 \mathrm{~kg} \mathrm{ha}^{-1} \mathrm{~N} / 21 \mathrm{~kg} \mathrm{ha}^{-1} \mathrm{P}_{2} \mathrm{O}_{5} / 4 \mathrm{~kg} \mathrm{ha}^{-1} \mathrm{~S}\right)$ are also provided. Other papers, such as Mloza-Banda et al. (2016), include information on the chemical weed control.

Some of the papers question CA definitions and are critical about them $(n=4)$. In some cases, farmers self-define what they consider CA principles or select the individual practices they implemented (e.g. only no till and residues, or only residue retention) $(n=4)$. In four cases, only two CA practices (no-till and residue retention) within the CA definition were tested (Ngwira et al. 2012b, 2014a; Thierfelder et al. 2013c; Khataza et al. 2018), and in some cases, CA adoption and preference were discussed per practice (Ward et al. 2016, 2018; Bell et al. 2018; Chinseu et al. 2019). The study by Khataza et al. (2018), for example, only focused on minimum tillage and residue retention because these were new practices in the study area. Lack of precision in the definition of CA and no-till systems 
Table 2 Selection criteria for this literature review

\begin{tabular}{ll}
\hline Included & Excluded \\
\hline English only & Global or African studies excluding Malawi \\
Available in Web of Science and Scopus & Climate Smart Agriculture in general \\
Conservation agriculture & Modelling only papers focusing on simulations \\
Peer-reviewed articles, reviews, book chapter & Conservation Agriculture not specifically mentioned \\
\hline
\end{tabular}

have been previously highlighted as lack of clarity about what the research or promotion is all about and what the results actually mean if incomplete CA systems are described, or where CA adoption is only short-lived (Chinseu et al. 2019).

The precision of treatment descriptions is often due to research or promotion taking place in controlled field trials, demonstrations or research stations. This provides the possibility to implement the needed treatment design control to enable comparison (e.g. Thierfelder et al. 2015b; Thierfelder et al. 2013a; Thierfelder et al. 2016a; Nyagumbo et al. 2016). These studies often represent context-specific variations of CA. This is reflected in the trial design variation in conventional practice, fertilizer recommendation, seeding practices $(n=13)$ or legumes or plant varieties $(n=13)$ to make it suitable for local adaptation and uptake.

For example, divisions for geographical areas can be found in Thierfelder et al. (2015b), the CA Malawi treatment is described as no-till with $2.5-3.0 \mathrm{t} \mathrm{ha}^{-1}$ residue retention rate, dibble stick planting, intercropping in one treatment with pigeonpea (Cajanus cajan L.) (southern) or cowpea (Vigna unguiculata L.) (central), $75 \mathrm{~cm}$ maize row spacing and $25 \mathrm{~cm}$ station spacing, whereas for Mozambique, basin planting with specific dimensions, similar residue retention rates and no till was used in one treatment and dibble stick or jab planter direct seeding in the other treatment. The used fertilizer rate of $58 \mathrm{~kg} \mathrm{ha}^{-1} \mathrm{~N} / 24 \mathrm{~kg} \mathrm{ha}^{-1} \mathrm{P}_{2} 0_{5} / 10 \mathrm{~kg} \mathrm{ha}^{-1} \mathrm{~K}_{2} 0$ is different from the one used in Malawi $\left(69 \mathrm{~kg} \mathrm{ha}^{-1} \mathrm{~N} / 21 \mathrm{~kg}\right.$ $\mathrm{ha}^{-1} \mathrm{P}_{2} 0_{5} / 4 \mathrm{~kg} \mathrm{ha}^{-1} \mathrm{~S}$ ). Glyphosate for weed control was used on clay soil types but manual weeding with hoes on sandy soils due to perceived environmental hazards on the very sandy soils. The rotation in similar trials in Zimbabwe and Zambia was done with cowpea (or soybeans in Northern Zimbabwe). Additionally, fertilizer rates were higher than Zimbabwe because of local blending and recommendation. The definition of the CA practices is therefore not subject to the farmers themselves but defined by researchers who are able to share the recorded details of these practices. The CA definition as stated by the FAO is based on the three core principles and allows for adaptation to the local system for inputs. Reviewing the literature, however, we find a difference in precision of the CA description and little information on how local input or plant variety adaptations impact CA's performance. This challenges comparing CA's performance between studies and eventually answering 'what forms of CA work, where, for whom and why?'

\subsection{Framing condition 2: what does it mean for CA to work?}

The most popular measures of success in most of the studies was increased yield or greater yield stability $(n=18)$. This metric of success is used both in the biophysical and economic assessment and in relation to soil health indicators. In TerAvest et al. (2015), yield is measured besides infiltration, soil moisture, $\mathrm{pH}$ and soil organic carbon, whereas Ngwira et al. (2012c) measures harvest, besides soil health indicators and profitability. Another popular measure of CA's success is gross margins, income and profitability change of farmers $(n=11)$. In some cases, these costs have been used as measurement of success in themselves, with value placed on metrics such as reduced labour and input costs, as well as ease of weeding (Johansen et al. 2012; Bunderson et al. 2017). In Ngwira et al. (2012a), an economic analysis in the form of partial budget analysis was used based on labour data in time per activity, prices of inputs and variable costs determined by the involved extension officer. The profit was determined with the use of average farm gate prices for maize and pigeon-pea. In Bunderson et al. (2017), income from harvest, costs and gross margins are calculated for $\mathrm{CA}$ and conventional tillage.

Other forms of quantitative bio-physical measures of CA efficacy used include various soil chemistry, physics or biology indicators such as soil structure, particle size, bulk density, aggregate stability $(n=9)$, carbon $(n=10)$, water infiltration, soil moisture, water tension or logging $(n=10)$, soil fauna $(n=5), \mathrm{pH}(n=4), \mathrm{N}(n=3), \mathrm{P}(n=2)$, erosion $(n=2)$, soil temperature $(n=1)$ or other chemical indicators such as $\mathrm{K}, \mathrm{Ca}$, $\mathrm{Zn}(n=1)$. Other measures of success include weed $(n=2)$ and pest suppression $(n=2)$. Even when considering specific metrics, there can be different ways of interpreting and understanding what it means for CA to 'work'. In case of the soil data, it often used to assess 'improvement' in soil health or soil quality. Soil quality is considered as looking at a combination of inherent and dynamic properties whereas soil health mainly focuses only on dynamics attributes (Bünemann et al. 2018). These concepts cover physical, chemical and biological indicators active on different timescales, or adapted to the soil function including the assigned indicator weights. MlozaBanda et al. (2014) and Mloza-Banda et al. (2016) have used a soil structural stability index, which considers soil physical factors. However, none of the other studies has used indices to quantify or make statements about soil health or quality but 
presented different properties or attributes in isolation without breaking them down to a single indicator.

The extent of CA adoption is also popular as a success indicator $(n=17)$ and can be used in numbers (e.g. how many adopters) or as practices (e.g. what practices are adopted) therefore being quantitative or qualitative. Although adoption is not a direct indicator of the biophysical or socio-economic efficacy of CA, it is sometimes assumed to be a proxy, and thus used as measure of success. In the case of adoption numbers, a majority of the research worked with a quantitative binary system suggesting adoption or non-adoption. Andersson and D'Souza (2014) in particular reflect on the methods that have been used to assess adoption, including the role of variation in definitions, input subsidies and project promotions. Recently, it has been suggested that a non-binary system accounting for the extent of adoption is more suitable because the definition of CA is variable across regions and full adoption is a rarity (Brown et al. 2017). This is supported by studies addressing CA (dis)adoption as preferences and adoption of individual practices change through time (Ward et al. 2016; Bell et al. 2018; Chinseu et al. 2019).

Some studies use qualitative only measures of success such as CA adaptation to local conditions $(n=4)$. For example, Kaluzi et al. (2017) conducted interviews and a survey with farmers to assess their decision making and CA adaptation. They found that $58 \%$ did not adapt CA to their context because they followed the exact guidelines of extension services. Additionally, they pointed out that $>50 \%$ of the farmerproposed solutions were not documented by extension officers, as they were not considered proven (Kaluzi et al. 2017). In our review, there were ten papers, of which nine from 2017 to 2019, that explicitly used farmers' attitude, motivation and transfer of knowledge as a measure of success. Only in four cases the dissemination of the innovation, familiarity with CA, demonstrations and farmers' recommendation are used as a measure of success (Fisher et al. 2018; Holden et al. 2018; Brown et al. 2018b; Khataza et al. 2018). In Fisher et al. (2018), CA adoption was analysed as a two-step process including first familiarity with the technology in relation to adoption, showing that lead farmers' familiarity and adoption of CA technologies increase likeliness of followers' familiarity. In four studies, the information from different stakeholders was discussed, thereby examining institutional and policy advocacy. In the case of Brown et al. (2018c), the perspective from local researchers was examined, and in Brown et al. (2018b), the perspective of agricultural extension providers. Furthermore, the study based on a national multi-stakeholder workshop by Dougill et al. (2017) shed light on the perspective of 18 key institutions including government, CGIAR, NGOs and the National Smallholder Farmer Association of Malawi (NASFAM). Reviewing the measures of success, there is a variety of agro-ecological and socio-economic indicators of success, which are rarely integrated or combined. In particular, the quantitative methods in the agro-ecological or economic disciplines are popular measures for assessing if CA works.

\subsection{Framing condition 3: where and for whom?}

Across the reviewed studies, a variety of variables are considered in order to determine the conditions under which CA works. The most common conditions tested are spatial differences in agro-ecological variables, including climate conditions $(n=26)$ and soil type $(n=23)$. Soil type and climatic conditions, in particular rainfall, play a crucial role in attaining CA's benefits with studies finding that CA's benefits are especially apparent in drier environments and low fertility soils (Ngwira et al. 2012c; Thierfelder et al. 2013b, 2015a, c; Nyagumbo et al. 2016). In the study by Cheesman et al. (2016), soil carbon and bulk density were measured in two regions in Malawi ( 7 communities), 3 provinces in Mozambique (10 communities), 1 province (1 community) in Zambia and 3 provinces (5 communities) in Zimbabwe. Only few articles mentioned livestock density or ownership, and its relation to mulching practices, as a condition tested for in relation to CA performance $(n=5)$. In Ngwira et al. (2014b), Tropical Livestock Unit is selected as an explanatory variable to understand if a higher livestock density will lead to more residue competition and therefore lower adoption likelihood.

Conditions in communities or real-world farming systems (as opposed to controlled trial sites) are less controllable and therefore the line between the tested conditions and the contextual conditions can be vague. Demographic information $(n=$ 11) about the contexts that is provided in some studies includes, gender $(n=9)$, education $(n=9)$, household size $(n=8)$, marriage status $(n=6)$, production $(n=5)$, duration CA practice $(n=3)$, resource access and poverty $(n=8)$, labour $(n=8)$, land size $(n=7)$, age $(n=7)$, CA practices adoption $(n=7)$, CA or off farm income $(n=3)$ and input subsidy $(n=4)$. The study by Kaluzi et al. (2017), for example, presents demographic data for the various communities in which the surveys have taken place but does not explicitly use them as explanatory variables. On the other hand, the demographic data in the paper by Ngwira et al. (2014b) are used as explanatory variables (e.g. education, family size, gender, age, labour, input subsidy and farmer group membership) for their analysis of CA adoption, using statistical inferences. Other commonly described conditions which make the research context unique are the introduction, promotion and history of CA and the institutional setting and NGO involvement $(n=17)$. Furthermore, papers focusing on farmer attitudes report on the farmer exposure, knowledge and motivation as conditions $(n=16)$. Some recorded significant factors affecting CA adoption rates are gender (Holden et al. 2018; Ward et al. 2018), hired labour (Ngwira et al. 2014b), maximum education (Ward et al. 2018), peer compliance (Ward et al. 2018), area 
location (Ngwira et al. 2014b; Ward et al. 2018), age (Holden et al. 2018; Makate et al. 2019), number of incentives or trainings received (Holden et al. 2018), support from farmer organization or non-faith based NGOs (Ward et al. 2016), land size of cultivated land (Ngwira et al. 2014b; Ward et al. 2016; Makate et al. 2019), household contact to extension (Makate et al. 2019), farmer group membership (Ngwira et al. 2014b), current practice of one of the three CA practices (Ward et al. 2016) and crop loss due to rainfall or insects (Ward et al. 2016).

Another discussed factor for CA's assessment is the role of social networks and social groups $(n=12)$, including farmer schools, farmer-to-farmer networks or NGO memberships. Two studies in particular tested the role of social networks and its impact on CA adoption. The study by Fisher et al. (2018) discusses the role lead farmers (and the farmer to farmer extension) play in the adoption and familiarity with CA. They showed that lead farmer adoption and familiarity affects CA distribution, and their motivation enhances the CA implementation by their followers. The paper by Holden et al. (2018) also focused on the role lead farmers played using a promoter-adopter approach. They concentrate on the CA practices recommendation to followers by the lead farmers, of which $45 \%$ would recommend minimum tillage, $27 \%$ mulching and 49\% crop rotation (Holden et al. 2018).

Time also plays an important role in CA research as a condition due to benefits in the form of yield only being recorded after a couple of years $(n=14)$. Additionally, time is also tested as a condition based on the assumption that the longer farmers are exposed to CA to more likely they gain knowledge, or adopt CA (Cheesman et al. 2017). Reading across the literature, the conditions tested under which CA works and the approach to testing these conditions varies.
Whereas in the agro-ecological studies, these tested conditions are more controlled (e.g. soil type, climate, varieties), the line between the tested and contextual conditions in the socioeconomic studies is less distinctive.

\subsection{Clustered framing conditions}

The identified codes were divided according to the themes that were found when analysing the papers for the framing conditions (Table 3$)$. These codes were assigned binary values $(1=$ present, $0=$ absent) to enable a cluster analysis.

A distinction between clusters of literature can be observed based on the tested conditions, success metrics and definition as shown in the dendrogram (Fig. 2). The dendrogram shows two main clusters and further subdivision intro three sub-clusters. When considering the literature in each of the clusters, it shows that the first cluster can be characterised as having a predominantly agro-ecological focus. The sub-division into two clusters (numbers 1 and 2) is caused by the use of econometric metrics of success (e.g. input prices, yield income, labour hours per activity) in the papers in cluster 2 . These papers therefore use a technical definition, trial conditions and agro-ecological measurements but additionally use profits as a measure of success and considered conditions. The two sub-clusters ( $a$ and $b$ ) within cluster 1 are caused by a difference in success measurements. Sub-cluster a does not include soil measurements, whereas sub-cluster $b$ does. The subclustering within cluster 2 can be explained by the type of paper. Sub-cluster a includes two review papers and discusses more factors for framing condition 2 (what does it mean for CA to work?) than the papers in sub-cluster b. In sub-cluster 2, there is a single branch to one paper that focuses on

Table 3 Codes used for cluster analysis, based on literature provided answers to the three framing conditions. $n$ shows how many study was identified with a 'yes' response to the code

\begin{tabular}{|c|c|c|c|c|c|}
\hline Framing condition 1 : what is CA? & $n$ & $\begin{array}{l}\text { Framing condition } 2 \text { : what does it } \\
\text { mean for CA to work? }\end{array}$ & $n$ & $\begin{array}{l}\text { Framing condition } 3 \text { : where and } \\
\text { for whom? }\end{array}$ & $\mathrm{n}$ \\
\hline CA self-defined & 4 & Yield & 18 & Climate conditions & 27 \\
\hline Critical evaluation of CA definition & 4 & Income, labour, input costs and profit & 11 & Soil type & 24 \\
\hline $\begin{array}{l}\text { Three basic CA principles } \\
\text { but not pre-scripted }\end{array}$ & 19 & Soil Chemistry & 11 & Livestock density or ownership & 5 \\
\hline CA Technical prescription & 20 & Soil Physics & 12 & Household Demographics & 11 \\
\hline \multirow[t]{7}{*}{ Additional practices and guidelines } & 27 & Soil Biology & 5 & Resources & 22 \\
\hline & & Weed and Pests & 4 & Labour & 17 \\
\hline & & Adoption & 17 & Land size & 7 \\
\hline & & Farmer attitude and transfer of knowledge & 10 & $\begin{array}{l}\text { Promotion history and institutional } \\
\text { involvement }\end{array}$ & 17 \\
\hline & & CA Adaptation & 4 & $\begin{array}{l}\text { Farmer exposure knowledge and } \\
\text { motivation }\end{array}$ & 16 \\
\hline & & Institutional and policy advocacy & 4 & Social networks and groups & 12 \\
\hline & & & & Cropping system and plant varieties & 21 \\
\hline
\end{tabular}


Fig. 2 Dendrogram showing clusters based on the reviewed literature hierarchical cluster analysis in SPSS 23.0.0.2. Cluster 1 shows agro-ecological studies, cluster 2 shows agro-ecological and econometrics studies and cluster 3 socio-economic studies
Thierfelder, Mombeyarara et al. 2013

Mupangwa et al. 2017

Nyagumbo et al. 2016

Ngwira, Aune et al. 2014

Thierfelder, Matemba-Mutasa et al. 2015

Mloza-Banda et al 2016

Ngwira, Sleutel et al. 2012

Mloza-Banda et al. 2014

TerAvest et al. 2015

Thierfelder, Chisui et al. 2013

Cheesman et al. 2016

Thierfelder et al. 2013

Thierfelder et al. 2015

Johansen et al. 2012

Thierfelder, Bunderson et al. 2015

Ngwira, Thierfelder et al. 2012

Thierfelder et al. 2016

Ngwira, Thierfelder et al. 2013

Ngwira et al. 2012

TerAvest et al. 2019

Thierfelder, Matemba-Mutasa et al. 2016

Bunderson et al. 2017

Mutenje et al. 2019

Brown et al. 2018

Brown, Nuberg et al. 2018

Dougill et al. 2017

Brown et al. 2017

Kaluzi et al. 2017

Ndah et al. 2014

Chinseu et al. 2019

Ward et al. 2016

Fisher et al. 2018

Ward et al. 2018

Holden et al. 2018

Ngwira et al. 2014

Bell et al.2018

Makate et al. 2019

Khataza et al. 2018

Brown, Nuberg et al. 2017

Andersson \& D'Souza 2014

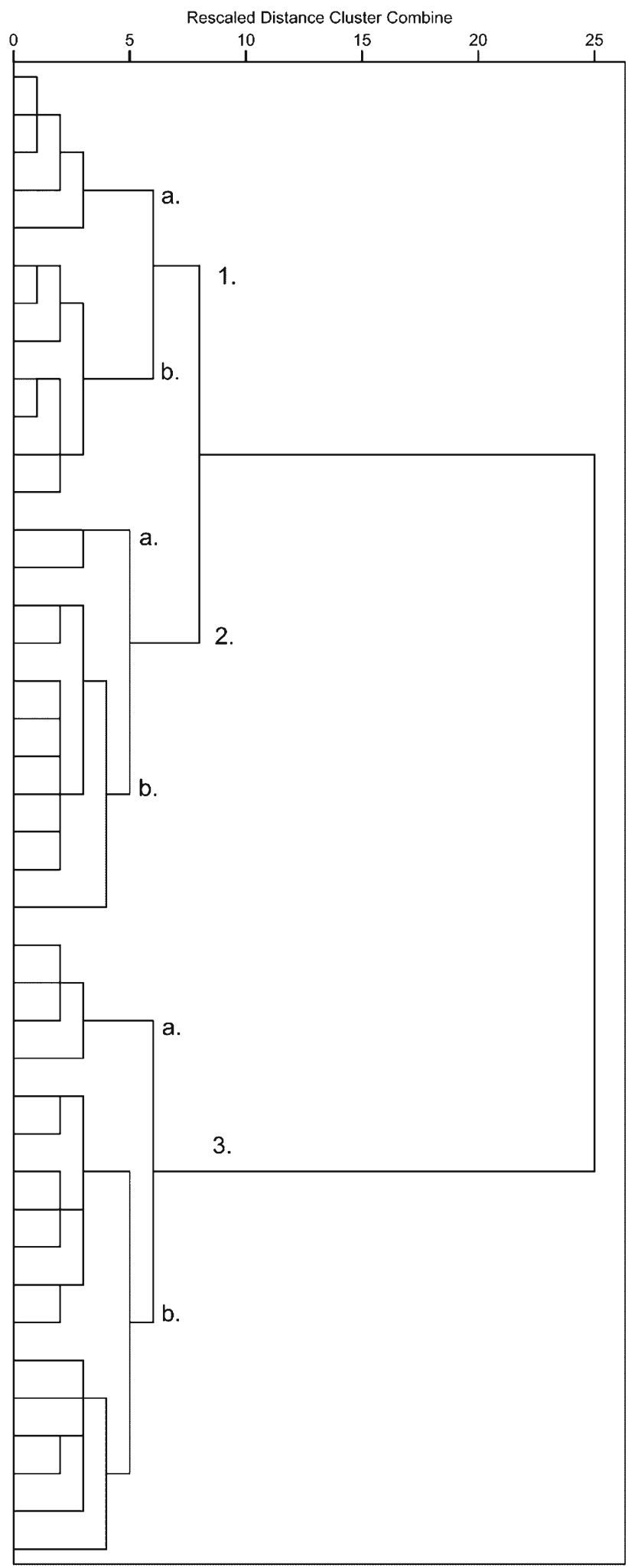

pre-scripted due to controlled trials. Its success is often measured in quantitative results on agro-ecological parameters (e.g. soil, yield) or including quantitative econometrics. The 'where and whom' part of the question are most frequently 
addressed in terms of different climate and environmental contexts, such as soil type, cropping system, and rainfall.

Cluster 3 consists out of the social science literature using basic three CA principles only without further prescriptions. This cluster focuses on transfer of knowledge, institutional context or household demographics as success metrics or research conditions. The clustering within this group is due to the inclusion of an institutional focus in the sub-cluster a papers as opposed to the papers in cluster $b$ that do not include an explicit institutional focus. The approach to the 'what' part of the question is therefore not pre-scripted but based on the three concepts, self-defined by farmers or critically discussed. The success metrics in this group are both quantitative in terms of adoption numbers and economic demographics, but also qualitative in terms of farmers attitude and transfer of knowledge. The 'where and for whom' conditions in this cluster are diverse due to the acknowledgement of diverse farming community contexts. The characteristics of these clusters therefore show that they have a distinct approach to the 'what, where, for whom' questions.

The identified agro-ecological and socio-economic clusters reflect epistemological differences. Cluster 2 may intersect the disciplines of agro-ecology and econometrics, but it is based on agro-ecological definitions and conditions and is oriented towards realism and objectivism. It uses economic data collected in researcher-controlled environments through surveys or interviews as measure of success. On the other hand, socioeconomic cluster 3 is increasingly embedded in subjectivism. However, most studies in cluster 3 still utilise researchercontrolled interviews, focus groups and surveys for data collection. Therefore, the level of participatory methods or ethnography is higher in the socio-economic cluster, but only two papers self-acclaim utilizing participatory questions or methods (Ndah et al. 2014; Dougill et al. 2017). In one case, the context in which the research is conducted, which also serves the purpose of CA dissemination, is acclaimed as participatory (Bunderson et al. 2017). Additionally, there was only one study, based in cluster 3, using an ethnographic approach (Bell et al. 2018).

A majority of the agro-ecological papers are based on data from CIMMYT field trials, both on-farm and from research stations. The reviewed literature in this cluster is predominantly published in agricultural and soil journals. A review of the journals cited by the included papers shows that the studies cite mostly crop, soil and agronomy journals (e.g. Soil \& Tillage Research, Field Crops Research, Soil Science Society of America Journal). In the socio-economic papers, there is a larger diversity in authors and research groups. A majority of the papers in this cluster are published in the last 2 years, whereas in the agro-ecological cluster, the studies have a longer age range, with only three papers from the last 2 years. The journals for publication of the socio-economic literature are land management and sustainability focused.
The cited literature in these studies is widely drawn from economics, management, sustainability and development journals (e.g. American Journal of Agricultural Economics, Agricultural Economics, Food Policy, The Journal of Agricultural Education and Extension). Additionally, the cited literature in this cluster shows a higher diversity in cited journals compared to the agro-ecological papers. Therefore, there are articles (e.g. Giller et al. 2009; Kassam et al. 2009; Thierfelder et al. 2013c, 2015c; Andersson and D'Souza 2014) cited across the literature but the review of the authors, journals and cited journals shows that there is a distinction between the clustered discipline groups.

\subsection{Framing condition 4: why?}

Our analysis of the different clusters of papers shows that within the agro-ecological cluster, it is more common to use a hypothesis, which is tested on controlled research stations and trials. This does not always result in understanding the drivers behind these measurements (thus answering the "why part" of the research question in this study). For example, the papers using soil health indicators typically use process-based arguments to justify chosen indicators. Statistical models are applied to show a relation between contextual factors and yield data. These include the treatment (CA vs non-CA), CA concepts, site or season $(n=14)$, or specifically soil type and rainfall $(n=1)$. More commonly, statistics are used to check the soil indicator results per treatment, such as $\mathrm{C}$ or $\mathrm{N}$ indicators $(n=8)$, water dynamics $(n=8)$ or soil chemical and physical attributes $(n=6)$. Only in a few studies were soil health indicators used in statistical tests to examine relation to yield or interaction $(n=4)$; therefore, a significant number of soil physical or soil chemistry results are reported without insight on the pathways leading up to the observed yield result or water dynamics.

Within the socio-economic cluster, there are different approaches to handling the why question, which can be qualitative or quantitative. In cases where data is collected in the form of demographic results for context description, statistics were used to assess the interaction and most influential factors based on the demographic results such as household size, gender, site or education. In other papers, qualitative responses were collected and shown in frequency numbers or used to show the diversity of answers and possible drivers of decision-making (e.g. Kaluzi et al. 2017). The qualitative approach and demographic statistical models especially focus on the 'why' part of the question including the drivers of decision-making. This cluster therefore has a stronger focus on the why part of the question which will be accompanied by contexts addressing the 'what, where and for whom'. However, the less controllable research conditions and complex farming community contexts make these drivers difficult to extrapolate or generalise. 


\section{Characterising and comparing disciplinary approaches to evaluating CA in Malawi}

The systematic literature review and analysis presented here reveal a clear distinction in approaches to CA research. Our analysis demonstrated that there is a sub-clustering in the agronomic studies (cluster 1 and 2), where some studies include an economic analysis with the biophysical metrics. These studies do still apply a technical CA definition, use quantitative metrics and often controlled conditions. Conversely, there are socio-economic studies that have looser (sometimes farmer-defined) definitions of what $\mathrm{CA}$ is, have socioeconomic (increasingly qualitative) metrics of success and do not have well-controlled variables to test. The distinct approaches lead to only partial answers to the key question of what forms of CA work, where, for whom and why? and create knowledge gaps that exist in the gap between the approaches.

The illustrated clustering represents two distinct ontologies and epistemologies. Natural science is oriented towards realism (ontology) and objectivism (epistemology). This means that it strives for objective empirical observation with the use of scientific methods, assuming one independent objective reality (e.g. measured biophysical results on CA trials) (Crotty 1998; Moon and Blackman 2014). On the other hand, the socio-economic literature can also be embedded in relativism (ontology), constructionism or subjectivism (epistemology) (Crotty 1998; Moon and Blackman 2014). These studies therefore focus on the interaction between object (e.g. CA) and subject (e.g. farmers), considering the subject's context such as history, culture and morality. These differences in approaches to agronomic research questions and the need to integrate these forms of knowledge can also be found in other agronomical debates such as System of Rice Intensification (SRI) (Sumberg et al. 2012). These distinct approaches are products of embedded methodologies, framings or principles; therefore, they are self-reinforcing and challenging to bridge (Whitfield 2015). When the goal is to cross these disciplinary divides, it means not only methods will need to be integrated but also the associated ontologies.

\section{The knowledge gaps that persist at the intersection of these disciplines}

In controlled studies, it is difficult to account for the multiple ways in which farmers practice and adapt CA, the multiple metrics of success that they might apply in evaluating it, or the diversity of socio-economic and agro-environmental conditions that might affect this 'success'. The precision with which the agricultural practices on research stations (or researcher managed on-farm trials) are carried out create 'high internal validity' and enables an exact and robust evaluation of the innovation, as required in (biophysical) agronomic research (Stevenson et al. 2014). At the same time, this limits the research by not accounting for socio-economic conditions and farmers' decision making (Giller et al. 2011; Stevenson et al. 2014). The feasibility and suitability of these agricultural practices for smallholder farmers are not reflected in these studies. The socio-economic studies trying to fill this knowledge gap are more at risk of doubtful internal validity because of challenges such as farmer heterogeneity and participant selection bias (Stevenson et al. 2014). In socio-economic studies, there is a lack of systematic, replicable documentation of agronomic conditions, practices and success metrics. It is therefore difficult to create an understanding of what works where and why, from these contextualised studies.

The lack of compatible data and metrics across these different types of studies means that it is difficult to integrate across these clusters to build a more complete picture of what forms of CA work, where, for whom, and why?, in particular the why part of this question. Detailed biophysical data is rarely collected as part of community-based research, nor are socio-economic metrics of success as part of controlled field trial experiments. It is uncommon to use controlled experimentation to systematically test the insights that come from community research. Additionally, the biophysical conditions on farms are often not commonly compared with those of trial situations.

The knowledge gaps that exist in the space between the varying approaches can assist with answering the why question. One of these gaps concerns the way in which different forms of knowledge are communicated and interpreted within farming communities, often organised around lead farmer and demonstration plot models by external organisation for the purpose of conservation agriculture promotion. It has been suggested that $\mathrm{CA}$ is a knowledge and management intensive agricultural technology, which might challenge its adoption in farming communities (Wall 2007; Giller et al. 2009). This requires examination of how agronomic knowledge is transferred within farming communities and if time will increase exposure and knowledge or if other factors are at play (Cheesman et al. 2017; Fisher et al. 2018; Holden et al. 2018). The different stakeholders involved and the agronomic nature of this technical information require both clusters to integrate for understanding these challenges and knowledge gaps. Furthermore, the processes through, which $C A$ principles and practices are experimented within and adapted to different systems and different farm level priorities, requires an interdisciplinary study of the interactions between socioeconomic and agronomic processes. Socio-economic studies can contribute to looking into the challenges such as 'the mindset of the plough' (Andersson and D'Souza 2014) through understanding farmer decision-making, prioritization and contextual importance, but this also requires experimentation and learning around the biophysical performance of $\mathrm{CA}$ 
practices and principles. The framing conditions and disciplinary analysis build on the work by Andersson and D'Souza (2014), which highlighted the socio-economic and institutional conditions of CA adoption, and Giller et al. (2011), which considered the research gaps on different levels from field to regional. The explicit focus on disciplinary approaches and epistemologies, developed here, adds to mapping the framing conditions of CA literature and identifying the challenges to interdisciplinary and integrated analyses. It supports the previous laid out CA research agenda's call for integrated and interdisciplinary studies (Giller et al. 2011, 2015). Additionally, it enables us to make recommendations to specifically improve integrated and interdisciplinary approaches to understand 'What works, where, for whom and why?.'

\section{Recommendations for alternative and interdisciplinary approaches in addressing these knowledge gaps}

To effectively address persistent knowledge gaps, new approaches are needed in studying what forms of CA work, where, for whom, and why? We acknowledge that farming systems are complex dynamic systems and that the discussion on farmers' adoption of new agricultural innovations has been ongoing for decades (Biggs 1989; Fujisaka 1994), including challenges that can be described as 'wicked' problems (Rittel and Webber 1973; Batie 2008). This shows that tensions may persist between approaches and that it is unlikely to find one single solution. However, improving interdisciplinary approaches such as FSR can support addressing the identified knowledge gaps. Here we briefly outline three methodological recommendations for advancing research at the intersections between the socio-economic and agronomic research traditions that currently dominate CA research.

Our first recommendation is about the products and protocols of research. Collecting a broad range of variables within both socio-economic and agronomic research, and making this data widely available in consistent and comparable formats, through platforms such as the CGIAR CSA initiative can offer more scope for collating and integrating mixed data from a common context, to inform meta-analysis research (CCAFS 2019). Because of the diversity and dynamic nature of farming systems, it is unrealistic for any individual research project to collect all possible variables over comprehensive spatial and temporal scales in order to fully validate comprehensive theories about CA. For this reason, there is real value in conducting meta-analyses across multiple datasets, which collectively better span the range of variables and scales. However, the strength of such analyses depends critically on the quality, compatibility and comprehensiveness of that collated data. Designed research with this in mind, with a view to making data accessible and computable for others, can contribute towards this broader endeavour of untangling and answering questions about what works, where, for whom and why. The yield data meta-regression by Steward et al. (2018) for example has illustrated the value of using collected data to answer the what and where parts of the question. To enable more meta-analyses like Steward et al. (2018), access to compatible, comprehensive and quality datasets is needed.

Secondly, we advocate for a methodological approach that draws strongly on a rich history of participation in farming systems research. Involving farmers and integrating local knowledges in the design and analysis of research across farming systems can contribute to a more thorough embedding of researching understandings of the local systems and broadening out of perspectives on why CA works (or does not work) in those contexts. To this end, there is value in advancing more ethnographic approaches to farming systems research. Ethnographic studies of innovation and technology development - termed technographic observation (Glover 2011) - provide rich insights into the values, philosophies and priorities of individuals, as well as the processes of social interaction, exchange and knowledge creation, that underpin farming practices. Process of experimentation and adaptation of farming practices are dynamic and change over time, and resistance to new technologies may be similarly rooted in long histories. Such conditions may only be realised and fully understood through research that is embedded in societies and cultures over time. There are already examples of disciplines focusing on local understanding of often scientifically approached natural phenomena, such as the field of ethnopedology which covers the indigenous classifications of soil and understanding of soil processes. Additionally, technographic observation as described in the case of SRI in Glover (2011) suggests asking more open-ended questions about new agricultural innovations, such as how it works in practice, and how this new knowledge flows into the current farmer practice systems. These kinds of approaches are the closest examples of bridging the ontological and epistemological perspectives described earlier.

Our third recommendation relates to the sites and structures of research. As a hybrid of controlled experimentation fields and household or community level research, we believe that on-farm experimentation and demonstration trials offer a valuable middle ground. This can contribute to achieving an interdisciplinary approach and potentially transdisciplinarity, where farmers are included in knowledge generation and interpretation. On-farm demonstration trials provide an opportunity to account for the more contextual information and data accepted in the agronomic research community (e.g. control fields, known quantities of herbicides and fertilizer) whereas the management by the farmer still allows for the community and cultural influence (Maat and Glover 2012; Wall et al. 2019). Research focused on on-farm demonstration trials is based on certain assumptions, such as the representativeness 
of on-farm trial results of new innovations for what farmers can accomplish on their own fields when the knowledge and experience is sufficient. These assumptions should be carefully handled and evaluated, but these trials offer the possibility to study multiple aspects, including technographic observation and their interactions around conservation agriculture.

The participation of farmers can take various forms depending on the aim and project phases. Biggs (1989) provide various examples of resource-poor farmer participation in research and describes four forms of participation: (1) contractual-farmers are contracted to provide a service or land; (2) consultative - farmers are consulted about their challenges which will feed into solution development; (3) collaborative - farmers and scientists are partners in the research; (4) collegial - the focus is to enhance informal development and research systems already in place. To increase participatory processes to answer "what forms of CA work, where, for whom, and why?', it is important to tap into the informal research and development systems, local knowledge and extension systems. The collaborative and collegial mode provides the most potential for this. However, these forms of participation require understanding of institutional and political settings, and socio-economic barriers of participants and proper organisation of two-way communication is crucial (Biggs 1989). Furthermore, the level of interaction of the different participants including biases in selection and roles, and meeting design (in addition to trials and surveys) is important for creating interdisciplinary and participatory research processes (Biggs 1989). The presence of various disciplines does not automatically result in well-integrated studies. The management should enable timely iterative review and assessment of the goal relevant information (Biggs 1989). An increasing involvement of social scientists and ethnography can provide valuable support to reaching this level of participation, organisation and integration.

It is important to note that on-farm trials can fall into specific discipline studies, and therefore, it is not the solution in itself. The work on on-farm trials provides an opportunity to incorporate different knowledge systems, incorporate control and complexity, and that can embrace quantitative and the qualitative methods. The CIMMYT on-farm trial literature such as Thierfelder et al. (2015a), Ngwira et al. (2012c) and Thierfelder et al. (2016a) shows the potential of examining biophysical, econometric and in the case of Thierfelder et al. (2015a) also socio-economic aspects around the on-farm demonstration trials. Another example is the mother-baby trial system in Snapp (2002) and Kerr et al. (2007), where a farmer research team supported by researchers maintained the mother trial with various legume technologies and 1-2 options were tested by individual farmers. There are different levels of farmer participation in on-farm research (Biggs 1989). Whereas the CIMMYT trials are on the side of controlled researcher-designed trials, participatory action research
(PAR) is a form of on-farm research where farmers are involved in the initial stages of research design and are included repetitive cycles of research, reflection and action (Ernesto Méndez et al. 2013, 2017). There is therefore potential to use the on-farm trials as middle ground for combining the approaches from different disciplines.

We believe that there is value in investing greater effort towards participatory and ethnographic research in and around on-farm experimentation and trial plots of $\mathrm{CA}$, in order to understand how farmers engage with, interpret and contribute to contextualised knowledge processes. Interpreting this evidence within broader systematic analyses of consistent and comprehensive datasets, which cross socio-economic and agro-ecological variables and cross temporal and spatial scales, can contribute significantly to understanding what forms of CA work, where, why and for whom.

\section{Conclusion}

This analysis of the CA literature in Malawi has shown that there are two distinct approaches, namely agro-ecological and socio-economic, to addressing the question of 'what forms of CA work, where, and why?' Neither of these approaches can address the full scope of this question on its own. The approaches are fundamentally different, which makes them incompatible and impossible to just read across this literature in order to answer the question. For example, the controlled conditions and strictly defined practices that are used in controlled trials to understand the agronomic performance of CA do not reflect the messy and often fluid realities of how it is adapted and applied on farms. The agronomic arguments do not necessarily translate well. Equally, the lack of systematic, replicable documentation of agronomic conditions, practices and performance in research on farming communities means that it is difficult to scale out our understanding of what works where and why, beyond the confines of the trial site.

Some of the knowledge gaps exist in the space between these two approaches. Examples are our understanding of how knowledge and information are constructed and communicated across scales, and how different and contextualised knowledges shape on-farm decision making around the adoption and adaptation of CA. We suggest that on-farm trials provide an opportunity for decreasing the space between different approaches and increase the connectivity of studies from across different disciplinary realms. Approaches such as technographic observations around these on-farm trials can provide a new approach that includes both the technical and social aspects of the CA studies. The on-farm trial provides a promising space for interdisciplinary epistemology and ontology, which incorporate different knowledge systems, qualitative and quantitative methods, control and complexity. Interpreting findings from integrated studies within broader 
meta-analyses of comprehensive and cross-scale datasets will help us to better understand what forms of CA work, where, for whom and, crucially, why.

Funding information The research presented in this paper was supported by the NERC DTP spheres grant NE/L002574/1. Financial support was maid available by the MAIZE CGIAR Research Program (www.maize. org) who provided staff time to contribute to this study. This study was partly funded by the UK Research and Innovation as part of the Global Challenges Research Fund AFRICAP project, BB/P027784/1.

\section{Compliance with ethical standards}

Conflict of interest The authors declare that they have no conflict of interest.

Open Access This article is licensed under a Creative Commons Attribution 4.0 International License, which permits use, sharing, adaptation, distribution and reproduction in any medium or format, as long as you give appropriate credit to the original author(s) and the source, provide a link to the Creative Commons licence, and indicate if changes were made. The images or other third party material in this article are included in the article's Creative Commons licence, unless indicated otherwise in a credit line to the material. If material is not included in the article's Creative Commons licence and your intended use is not permitted by statutory regulation or exceeds the permitted use, you will need to obtain permission directly from the copyright holder. To view a copy of this licence, visit http://creativecommons.org/licenses/by/4.0/.

\section{References}

Andersson JA, D’Souza S (2014) From adoption claims to understanding farmers and contexts: a literature review of conservation agriculture (CA) adoption among smallholder farmers in southern Africa. Agric Ecosyst Environ 187:116-132. https://doi.org/10.1016/j.agee.2013. 08.008

Andersson JA, Giller KE (2012) On heretics and god 's blanket salesmen : contested claims for conservation agriculture and the politics of its promotion in African smallholder farming. In: Sumberg J, Thompson $\mathrm{J}$ (eds) Contested agronomy: agricultural research in a changing world. Earthscan, Routledge, Abingdon, Oxon, pp 22-46

Antwi-Agyei P, Dougill AJ, Stringer LC (2015) Barriers to climate change adaptation: evidence from Northeast Ghana in the context of a systematic literature review. Clim Dev 7:297-309. https://doi. org/10.1080/17565529.2014.951013

Asfaw S, Orecchia C, Pallante G, Palma A (2018) Soil and nutrients loss in Malawi: an economic assessment. www.fao.org/publications. Accessed 28 May 2019

Batie SS (2008) Wicked problems and applied economics. Am J Agric Econ 90:1176-1191. https://doi.org/10.1111/j.1467-8276.2008. 01202.x

Bell A, Zavaleta Cheek J, Mataya F, Ward P (2018) Do as they did: peer effects explain adoption of conservation agriculture in Malawi. Water 10:51. https://doi.org/10.3390/w10010051

Biesbroek GR, Klostermann JEM, Termeer CJAM, Kabat P (2013) On the nature of barriers to climate change adaptation. Reg Environ Chang 13:1119-1129. https://doi.org/10.1007/s10113-013-0421-y

Biggs SD (1989) Resource-poor farmer participation in research: a synthesis of experiences from nine National Agricultural Research Systems. Netherlands, The Hague
Brown B, Nuberg I, Llewellyn R (2017) Negative evaluation of conservation agriculture: perspectives from African smallholder farmers. Int J Agric Sustain 15:467-481. https://doi.org/10.1080/14735903. 2017.1336051

Brown B, Llewellyn R, Nuberg I (2018a) Global learnings to inform the local adaptation of conservation agriculture in eastern and southern Africa. Glob Food Sec 17:213-220. https://doi.org/10.1016/j.gfs. 2017.10.002

Brown B, Nuberg I, Llewellyn R (2018b) Constraints to the utilisation of conservation agriculture in Africa as perceived by agricultural extension service providers. Land Use Policy 73:331-340. https://doi. org/10.1016/j.landusepol.2018.02.009

Brown B, Nuberg I, Llewellyn R (2018c) Research capacity for local innovation: the case of conservation agriculture in Ethiopia, Malawi and Mozambique. J Agric Educ Ext 24:249-262. https:// doi.org/10.1080/1389224X.2018.1439758

Bunderson WT, Jere ZD, Thierfelder C et al (2017) Implementing the principles of conservation agriculture in Malawi: crop yields and factors affecting adoption. In: Kassam AH, Mkomwa S, Friedrich $\mathrm{T}$ (eds) Conservation agriculture for Africa: building resilient farming Systems in a Changing Climate. CABI, Wallingford, pp 75-99

Bünemann EK, Bongiorno G, Bai Z et al (2018) Soil quality - a critical review. Soil Biol Biochem 120:105-125. https://doi.org/10.1016/j. soilbio.2018.01.030

CCAFS (2019) Climate-Smart Technologies and Practices | CCAFS: CGIAR research program on Climate Change, Agriculture and Food Security. https://ccafs.cgiar.org/flagships/climate-smarttechnologies-and-practices. Accessed 27 Aug 2019

Cheesman S, Thierfelder C, Eash NS et al (2016) Soil carbon stocks in conservation agriculture systems of southern Africa. Soil Tillage Res 156:99-109. https://doi.org/10.1016/j.still.2015.09.018

Cheesman S, Andersson JA, Frossard E (2017) Does closing knowledge gaps close yield gaps? On-farm conservation agriculture trials and adoption dynamics in three smallholder farming areas in Zimbabwe. J Agric Sci 155:81-100. https://doi.org/10.1017/ S0021859616000095

Chinseu E, Dougill A, Stringer L (2019) Why do smallholder farmers disadopt conservation agriculture? Insights from Malawi. L Degrad Dev 30:533-543. https://doi.org/10.1002/ldr.3190

Collinson MP (2000) A history of farming systems research. CABI, Wallingford

Crotty M (1998) The foundations of social research meaning and perspective in the research process. SAGE, London

Dougill AJ, Whitfield S, Stringer LC, Vincent K, Wood BT, Chinseu EL, Steward P, Mkwambisi DD (2017) Mainstreaming conservation agriculture in Malawi: knowledge gaps and institutional barriers. J Environ Manag 195:25-34. https://doi.org/10.1016/j.jenvman. 2016.09.076

Ernesto Méndez V, Bacon CM, Cohen R (2013) Agroecology as a transdisciplinary, participatory, and action-oriented approach. Agroecol Sustain Food Syst 37:3-18

Ernesto Méndez V, Caswell M, Gliessman SR, Cohen R (2017) Integrating agroecology and participatory action research (PAR): lessons from Central America. Sustainability 9:1-19. https://doi. org/10.3390/su9050705

FAO (2008) Investing in sustainable agricultural intensification. The role of conservation agriculture. Rome

FAO (2015) Conservation Agriculture. http://www.fao.org/conservationagriculture/en/. Accessed 27 May 2019

Fisher M, Holden ST, Thierfelder C, Katengeza SP (2018) Awareness and adoption of conservation agriculture in Malawi: what difference can farmer-to-farmer extension make? Int J Agric Sustain 16:310-325. https://doi.org/10.1080/14735903.2018.1472411

Fujisaka S (1994) Learning from six reasons why farmers do not adopt innovations intended to improve sustainability of upland agriculture. 
Agric Syst 46:409-425. https://doi.org/10.1016/0308-521X(94) 90104-N

Giller KE, Witter E, Corbeels M, Tittonell P (2009) Conservation agriculture and smallholder farming in Africa: the heretics' view. F Crop Res 114:23-34. https://doi.org/10.1016/j.fcr.2009.06.017

Giller KE, Corbeels M, Nyamangara J et al (2011) A research agenda to explore the role of conservation agriculture in African smallholder farming systems. F Crop Res 124:468-472. https://doi.org/10.1016/ j.fcr.2011.04.010

Giller KE, Andersson JA, Corbeels M et al (2015) Beyond conservation agriculture. Front Plant Sci 6:1-14. https://doi.org/10.3389/fpls. 2015.00870

Glaser BG, Strauss AL (1967) The discovery of grounded theory: strategies for qualitative research. AldineTransaction, New Brunswick

Glover D (2011) The system of Rice intensification: time for an empirical turn. NJAS - Wageningen J Life Sci 57:217-224. https://doi.org/10. 1016/j.njas.2010.11.006

Grabowski PP, Kerr JM, Haggblade S, Kabwe S (2016) Determinants of adoption and disadoption of minimum tillage by cotton farmers in eastern Zambia. Agric Ecosyst Environ 231:54-67. https://doi.org/ 10.1016/j.agee.2016.06.027

Holden ST, Fisher M, Katengeza SP, Thierfelder C (2018) Can lead farmers reveal the adoption potential of conservation agriculture? The case of Malawi. Land Use Policy 76:113-123. https://doi.org/ 10.1016/j.landusepol.2018.04.048

IBM Corp (2015) IBM SPSS Statistics for Windows, Version 23.0

Johansen C, Haque ME, Bell RW et al (2012) Conservation agriculture for small holder rainfed farming: opportunities and constraints of new mechanized seeding systems. F Crop Res 132:18-32. https:// doi.org/10.1016/j.fcr.2011.11.026

Kaluzi L, Thierfelder C, Hopkins DW (2017) Smallholder farmer innovation and contexts in maize-based conservation agriculture Systems in Central Malawi. Sustain Agric Res 6:85. https://doi. org/10.5539/sar.v6n3p85

Kassam A, Friedrich T, Shaxson F, Pretty J (2009) The spread of conservation agriculture: justification, sustainability and uptake. Int J Agric Sustain 7:292-320. https://doi.org/10.3763/ijas.2009.0477

Kassam A, Friedrich T, Derpsch R (2019) Global spread of conservation agriculture. Int J Environ Stud 76:29-51. https://doi.org/10.1080/ 00207233.2018.1494927

Kerr RB, Snapp S, Chirwa M et al (2007) Participatory research on legume diversification with Malawian smallholder farmers for improved human nutrition and soil fertility. Exp Agric 43:437-453. https://doi.org/10.1017/S0014479707005339

Khataza RRB, Doole GJ, Kragt ME, Hailu A (2018) Information acquisition, learning and the adoption of conservation agriculture in Malawi: a discrete-time duration analysis. Technol Forecast Soc Change 132:299-307. https://doi.org/10.1016/J.TECHFORE.2018. 02.015

Leach M, Stirling A, Scoones I (2010) Dynamic sustainabilities: technology, environment, social justice. Earthscan, Routledge, Abingdon, Oxon

Lipper L, Thornton P, Campbell BM et al (2014) Climate-smart agriculture for food security. Nat Clim Chang 4:1068-1072. https://doi.org/ $10.1038 /$ nclimate 2437

Maat H, Glover D (2012) Alternative configurations of agronomic experimentation. In: Sumberg J, Thompson J (eds) Contested agronomy: agricultural research in a changing world. Routledge, Abingdon, Oxon, pp 131-145

Makate C, Makate M, Mango N, Siziba S (2019) Increasing resilience of smallholder farmers to climate change through multiple adoption of proven climate-smart agriculture innovations. Lessons from Southern Africa. J Environ Manage 231:858-868. https://doi.org/ 10.1016/j.jenvman.2018.10.069

Mloza-Banda ML, Cornelis WM, Mloza-Banda HR et al (2014) Soil properties after change to conservation agriculture from ridge tillage in sandy clay loams of mid-altitude Central Malawi. Soil Use Manag 30:569-578. https://doi.org/10.1111/sum.12139

Mloza-Banda HR, Makwiza CN, Mloza-Banda ML (2016) Soil properties after conversion to conservation agriculture from ridge tillage in southern Malawi. J Arid Environ 127:7-16. https://doi.org/10.1016/ j.jaridenv.2015.11.001

Moon K, Blackman D (2014) A guide to understanding social science research for natural scientists. Conserv Biol 28:1167-1177. https:// doi.org/10.1111/cobi.12326

Mupangwa W, Mutenje M, Thierfelder C, Nyagumbo I (2017a) Are conservation agriculture (CA) systems productive and profitable options for smallholder farmers in different agro-ecoregions of Zimbabwe? Renew Agric Food Syst 32:87-103. https://doi.org/10. 1017/S1742170516000041

Mupangwa W, Thierfelder C, Ngwira AR (2017b) Fertilization strategies in conservation agriculture systems with maize-legume cover crop rotations in southern Africa. Exp Agric 53:288-307. https://doi.org/ $10.1017 / \mathrm{S} 0014479716000387$

Mutenje MJ, Farnworth CR, Stirling C et al (2019) A cost-benefit analysis of climate-smart agriculture options in southern Africa: balancing gender and technology. Ecol Econ 163:126-137. https:// doi.org/10.1016/j.ecolecon.2019.05.013

Ndah HT, Schuler J, Uthes S, Zander P, Traore K, Gama MS, Nyagumbo I, Triomphe B, Sieber S, Corbeels M (2014) Adoption potential of conservation agriculture practices in sub-Saharan Africa: results from five case studies. Environ Manag 53:620-635. https://doi. org/10.1007/s00267-013-0215-5

Ngwira AR, Aune JB, Mkwinda S (2012a) On-farm evaluation of yield and economic benefit of short term maize legume intercropping systems under conservation agriculture in Malawi. F Crop Res 132:149-157. https://doi.org/10.1016/j.fcr.2011.12.014

Ngwira AR, Sleutel S, de Neve S (2012b) Soil carbon dynamics as influenced by tillage and crop residue management in loamy sand and sandy loam soils under smallholder farmers' conditions in Malawi. Nutr Cycl Agroecosystems 92:315-328. https://doi.org/10.1007/ s10705-012-9492-2

Ngwira AR, Thierfelder C, Lambert DM (2012c) Conservation agriculture systems for Malawian smallholder farmers: long-term effects on crop productivity, profitability and soil quality. Renew Agric Food Syst 28:350-363. https://doi.org/10.1017/S1742170512000257

Ngwira AR, Thierfelder C, Eash NS, Lambert DM (2013) Risk and maize-based cropping Systems for Smallholder Malawi Farmers Using Conservation Agriculture Technologies. Exp Agric 49:483503. https://doi.org/10.1017/S0014479713000306

Ngwira AR, Aune JB, Thierfelder C (2014a) On-farm evaluation of the effects of the principles and components of conservation agriculture on maize yield and weed biomass in Malawi. Exp Agric 50:591610. https://doi.org/10.1017/S001447971400009X

Ngwira AR, Johnsen FH, Aune JB et al (2014b) Adoption and extent of conservation agriculture practices among smallholder farmers in Malawi. J Soil Water Conserv 69:107-119. https://doi.org/10. 2489/jswc.69.2.107

Nyagumbo I, Mkuhlani S, Pisa C, Kamalongo D, Dias D, Mekuria M (2016) Maize yield effects of conservation agriculture based maizelegume cropping systems in contrasting agro-ecologies of Malawi and Mozambique. Nutr Cycl Agroecosystems 105:275-290. https:// doi.org/10.1007/s10705-015-9733-2

Pannell DJ, Llewellyn RS, Corbeels M (2014) The farm-level economics of conservation agriculture for resource-poor farmers. Agric Ecosyst Environ 187:52-64. https://doi.org/10.1016/j.agee.2013.10.014

Rittel HWJ, Webber MM (1973) Dilemmas in a general theory of planning. Policy Sci 4:155-169. https://doi.org/10.1007/BF01405730

Snapp SS (2002) Quantifying farmer evaluation of technologies: the mother and baby trial design. In: Bellon MR, Reeves J (eds) Quantitative analysis of data from participatory methods in plant breeding. CIMMYT, PRGA and IRRI, Mexico,DF, pp 9-18 
Stevenson JR, Serraj R, Cassman KG (2014) Evaluating conservation agriculture for small-scale farmers in sub-Saharan Africa and South Asia. Agric Ecosyst Environ 187:1-10. https://doi.org/10. 1016/j.agee.2014.01.018

Steward PR, Dougill AJ, Thierfelder C et al (2018) The adaptive capacity of maize-based conservation agriculture systems to climate stress in tropical and subtropical environments : a meta-regression of yields. Agric Ecosyst Environ 251:194-202. https://doi.org/10.1016/j.agee. 2017.09.019

Sumberg J, Thompson J, Woodhouse P (2012) Contested agronomy: agricultural research in a changing world. Earthscan, Routledge, Abingdon, Oxon

TerAvest D, Carpenter-Boggs L, Thierfelder C, Reganold JP (2015) Crop production and soil water management in conservation agriculture, no-till, and conventional tillage systems in Malawi. Agric Ecosyst Environ 212:285-296. https://doi.org/10.1016/j.agee.2015.07.011

TerAvest D, Wandschneider PR, Thierfelder C, Reganold JP (2019) Diversifying conservation agriculture and conventional tillage cropping systems to improve the wellbeing of smallholder farmers in Malawi. Agric Syst 171:23-35. https://doi.org/10.1016/j.agsy. 2019.01.004

Tesfaye K, Jaleta M, Jena P, Mutenje M (2015) Identifying potential recommendation domains for conservation agriculture in Ethiopia, Kenya, and Malawi. Environ Manag 55:330-346. https://doi.org/10. 1007/s00267-014-0386-8

The World Bank (2016) Rural population (\% of total population) $\mid$ Data. https://data.worldbank.org/indicator/SP.RUR.TOTL.ZS?locations= MW. Accessed 28 May 2019

Thierfelder C, Wall PC (2009) Effects of conservation agriculture techniques on infiltration and soil water content in Zambia and Zimbabwe. Soil Tillage Res 105:217-227. https://doi.org/10.1016/ j.still.2009.07.007

Thierfelder C, Wall PC (2010a) Investigating conservation agriculture (CA) systems in Zambia and Zimbabwe to mitigate future effects of climate change. J Crop Improv 24:113-121. https://doi.org/10. $1080 / 15427520903558484$

Thierfelder C, Wall PC (2010b) Rotation in conservation agriculture Systems of Zambia: effects on soil quality and water relations. Exp Agric 46:309-325. https://doi.org/10.1017/ S001447971000030X

Thierfelder C, Cheesman S, Rusinamhodzi L (2013a) Benefits and challenges of crop rotations in maize-based conservation agriculture (CA) cropping systems of southern Africa. Int J Agric Sustain 11: 108-124. https://doi.org/10.1080/14735903.2012.703894

Thierfelder C, Chisui JL, Gama M et al (2013b) Maize-based conservation agriculture systems in Malawi: long-term trends in productivity. F Crop Res 142:47-57. https://doi.org/10.1016/j.fcr.2012.11.010

Thierfelder C, Mombeyarara T, Mango N, Rusinamhodzi L (2013c) Integration of conservation agriculture in smallholder farming systems of southern Africa: identification of key entry points. Int $\mathrm{J}$ Agric Sustain 11:317-330. https://doi.org/10.1080/14735903. 2013.764222

Thierfelder C, Bunderson WT, Mupangwa W (2015a) Evidence and lessons learned from long-term on-farm research on conservation agriculture Systems in Communities in Malawi and Zimbabwe. Environments 2:317-337. https://doi.org/10.3390/ environments 2030317

Thierfelder C, Matemba-Mutasa R, Rusinamhodzi L (2015b) Yield response of maize (Zea mays L.) to conservation agriculture cropping system in southern Africa. Soil Tillage Res 146:230-242. https:// doi.org/10.1016/j.still.2014.10.015
Thierfelder C, Rusinamhodzi L, Ngwira AR et al (2015c) Conservation agriculture in southern Africa: advances in knowledge. Renew Agric Food Syst 30:328-348. https://doi.org/10.1017/ S1742170513000550

Thierfelder C, Bunderson WT, Jere ZD et al (2016a) Development of conservation agriculture $(\mathrm{Ca})$ Systems in Malawi: lessons learned from 2005 to 2014. Exp Agric 52:579-604. https://doi.org/10.1017/ S0014479715000265

Thierfelder C, Matemba-Mutasa R, Bunderson WT et al (2016b) Evaluating manual conservation agriculture systems in southern Africa. Agric Ecosyst Environ 222:112-124. https://doi.org/10. 1016/j.agee.2016.02.009

Thierfelder C, Chivenge P, Mupangwa W, Rosenstock TS, Lamanna C, Eyre JX (2017) How climate-smart is conservation agriculture (CA)? - its potential to deliver on adaptation, mitigation and productivity on smallholder farms in southern Africa. Food Secur 9: 537-560. https://doi.org/10.1007/s12571-017-0665-3

Thompson HE, Berrang-Ford L, Ford JD (2010) Climate change and food security in sub-Saharan Africa: a systematic literature review. Sustainability 2:2719-2733. https://doi.org/10.3390/su2082719

Valbuena D, Erenstein O, Homann-Kee Tui S et al (2012) Conservation agriculture in mixed crop-livestock systems: scoping crop residue trade-offs in sub-Saharan Africa and South Asia. F Crop Res 132: 175-184. https://doi.org/10.1016/j.fcr.2012.02.022

Vogel H (1994) Weeds in single-crop conservation farming in Zimbabwe. Soil Tillage Res 31:169-185. https://doi.org/10.1016/01671987(94)90078-7

Wall PC (2007) Tailoring conservation agriculture to the needs of small farmers in developing countries: an analysis of issues. J Crop Improv 1938:137-155. https://doi.org/10.1300/J411v19n01_07

Wall PC, Thierfelder CL, Nyagumbo I et al (2019) Comment on "De Roo et al. (2019). On-farm trials for development impact? the organization of research and the scaling of agricultural technologies". Exp Agric 55:185-194. https://doi.org/10.1017/S0014479718000492

Ward JH (1963) Hierarchical grouping to optimize an objective function. J Am Stat Assoc 58:236-244. https://doi.org/10.1080/01621459. 1963.10500845

Ward PS, Bell AR, Parkhurst GM et al (2016) Heterogeneous preferences and the effects of incentives in promoting conservation agriculture in Malawi. Agric Ecosyst Environ 222:67-79. https://doi.org/10.1016/ j.agee.2016.02.005

Ward PS, Bell AR, Droppelmann K, Benton TG (2018) Early adoption of conservation agriculture practices: understanding partial compliance in programs with multiple adoption decisions. Land Use Policy 70: 27-37. https://doi.org/10.1016/j.landusepol.2017.10.001

Whitfield S (2015) Adapting to climate uncertainty in African agriculture: narratives and knowledge politics. Earthscan, Routledge, Abingdon, Oxon

Whitfield S, Dixon JL, Mulenga BP, Ngoma H (2015a) Conceptualising farming systems for agricultural development research: cases from eastern and southern Africa. Agric Syst 133:54-62. https://doi.org/ 10.1016/j.agsy.2014.09.005

Whitfield S, Dougill AJ, Dyer JC et al (2015b) Critical reflection on knowledge and narratives of conservation agriculture. Geoforum 60:133-142. https://doi.org/10.1016/j.geoforum.2015.01.016

Publisher's note Springer Nature remains neutral with regard to jurisdictional claims in published maps and institutional affiliations. 